\title{
Thermal Burn Deaths: A Retrospective Study on Female Victims in Bihar
}

\author{
Ranjay Kumar Ranjan ${ }^{1}$, Radha Raman Singh ${ }^{2}$, Rajiv Ranjan Das ${ }^{3}$, \\ Mukti Nath Singh ${ }^{4}$, Manoj Kumar
}

\author{
${ }^{1}$ Junior Resident, Department of F.M.T, Nalanda Medical College, Patna, India \\ ${ }^{2,3,5}$ Associate Professor, Department of F.M.T, Nalanda Medical College, Patna, India \\ ${ }^{4}$ Prof. \& HOD Department of F.M.T, Nalanda Medical College, Patna, India
}

Corresponding Author: Radha Raman Singh

\begin{abstract}
Introduction: Burns are medicolegally importance as they are commonest cause of unnatural death in India. Burn is an important factor in suicide and homicide all over world. Burns remain a significant public health problem in low/middle-income countries, contributing to substantial morbidity and mortality
\end{abstract}

Aims \&Objectives: To find out how thermal burn affect incidence, age, habitat, marital status, manner of death and its medico legal consequence.

Materials and Methods: This retrospective study was carried out in a tertiary care hospital during 2014 to 2018 to assess the pattern of burn deaths amongst females brought for Medicolegal Autopsy from various police stations of Patna district under F.M.T department of N.M.C, Patna in the State of Bihar. Total 540 female burn cases brought for autopsy were included in study.

Results: The highest numbers of victims were in the age group of 21 to 30 years $(42.23 \%)$. Majority of the cases were from rural areas $75.19 \%$ and $81.85 \%$ of the victims were married. Mostly manner of death is accidental $57.40 \%$. Majority of the burn victims death of the studied case were Hindu.

Conclusion: Married females of productive age group belonging to rural areas are worst affected in burn injuries. Awareness campaigns targeting safety precautions, opportunities for basic health education and a change in mindset of society towards females are necessary to curb this menace of burn injuries.
Key words: Burn, Female, Nature of Death, Bihar

\section{INTRODUCTION}

Burns injuries are caused by the application of heat such as radiant heat, flame and some heated substances like metal or glass on the surface of the body resulting in destruction of tissues. In young population, about $40 \%$ burn is fatal. ${ }^{(\mathbf{1})}$ Burns are medicolegally importance as they are commonest cause of unnatural death in India. Often, the circumstances of burns are enveloped in mystery, obscurity and unreliable statements. ${ }^{(2)}$ Globally, there were over 33.5million thermal burn injuries in 2013, resulting in over 1 million years lost to disability, and approximately 237500 deaths. An estimated $90 \%$ of burn deaths, occur in low/middle-income countries. ${ }^{(3,4)}$ Burns remain a significant public health problem in low/middle-income countries , contributing to substantial morbidity and mortality. ${ }^{(5)}$ However, in India, where an estimated 163000 deaths occur annually due to fire-related injuries, the patterns of burns are different. ${ }^{(\boldsymbol{6})}$ In a study involving 222 patients who was admitted in tertiary care centre in India, the average TBSA of the 135 patients who died was $65.7 \%$ (SD $2.1 \%) .{ }^{(7)}$ The reasons for this endemic may be manifold like dowry, marital infidelity, sexual jealousy, and dominance of mother in law over the grooms, etc.

The commonest burn is accidental burn injury. ${ }^{(\mathbf{8})}$ Accidental burns are mostly 
seen in females especially housewives as they spend most of their time in household works especially related to cooking. Burn is an important factor in suicide and homicide all over the world. Sometimes people after doing criminal acts like rape, murder etc and for concealing the facts, they burn the body of crime. Dowry death is a subject of immense concern in our society in spite of strict laws and amendments. ${ }^{(9)} \mathrm{We}$ usually read in newspapers and see in media about the cases of women either being provoked or burnt to commit suicide by the husband and others just for the dowry. ${ }^{(10)}$ The present study has been taken up to assess the pattern of female deaths in this part of the country and factors associated with such female deaths.

\section{Aims \& Objectives}

To find out how thermal burn affect incidence, age, marital status, habitat, manner of death and its medico legal consequence.

\section{MATERIALS AND METHODS}

This retrospective study was carried out to assess the pattern of burn deaths amongst females brought for Medico-legal Autopsy during January 2014 to December 2018 from various police stations of Patna district under F.M.T department of N.M.C, Patna in the State of Bihar. During this period total of 540 female burn death cases were recorded out of 2265 medico-legal postmortem conducted. Total 540 female burn cases brought for autopsy were included in study. Controversial cases were excluded from the study. Information was collected through a pre-tested questionnaire from victims' relatives, perusal of hospital records.

\section{Data Collection and Statistical Analysis}

The data was recorded in the proforma drawn up specifically for the purpose of this study, checked manually for correction of some minor errors like digit mistake, wrong unit of measurements, data format mistakes etc.

The data was put in MS Excel spread sheet and statistical analysis performed using SPSS (Statistic Package for Social Sciences) version 20.0 software. and are analysed in the tables and figures.

\section{RESULTS}

Table 1: distribution of year wise cases of thermal burn death reported during the 5 year study period from 2014 to 2018 were $15.55 \%$, $17.78 \%, 20.74 \%, 22.23 \%, 23.70 \%$, respectively showing an increasing trend. This table also shows that total thermal burn death 540 which is $23.84 \%$ of total autopsy (2265) conducted.

\begin{tabular}{|c|c|c|c|c|}
\hline Year & Total autopsy case & $\mathbf{\%}$ & Thermal Burn Death & \% \\
\hline 2014 & 350 & 15.45 & 84 & 15.55 \\
\hline 2015 & 379 & 16.73 & 96 & 17.78 \\
\hline 2016 & 404 & 17.84 & 112 & 20.74 \\
\hline 2017 & 531 & 23.45 & 120 & 22.23 \\
\hline 2018 & 601 & 26.53 & 128 & 23.70 \\
\hline Total & $\mathbf{2 2 6 5}$ & $\mathbf{1 0 0}$ & $\mathbf{5 4 0}$ & $\mathbf{1 0 0}$ \\
\hline
\end{tabular}

Table 2: The highest number of victims were in the age group of 21 to 30 years $(42.23 \%)$. followed by $31-40$ years in the 5 year. Most of the victims of burn deaths were recorded at 21-40 year (which is more than half of the total burn death) with peak incidence at 21-30 year. Extremes of ages are least involved as compared to adult age group as seen in table.

\begin{tabular}{|c|c|c|}
\hline Age in years & Female & Percentage \\
\hline $11-20$ & 62 & 11.48 \\
\hline $21-30$ & 228 & 42.23 \\
\hline $31-40$ & 140 & 25.93 \\
\hline $41-50$ & 65 & 12.03 \\
\hline $51-60$ & 45 & 8.33 \\
\hline Total & $\mathbf{5 4 0}$ & $\mathbf{1 0 0}$ \\
\hline
\end{tabular}

Table3: Describe the marital status of the studied victim showing married female $(81.85 \%)$ outnumbered the unmarried female $(18.15 \%)$.

\begin{tabular}{|c|c|c|}
\hline Marital Status & Female & Percentage \\
\hline Married & 442 & 81.85 \\
\hline Unmarried & 98 & 18.15 \\
\hline
\end{tabular}

Table 4: show regarding manner of death, accidental $57.40 \%$, suicidal $23.14 \%$, unknown $12.60 \%$ and homicidal $6.85 \%$.

\begin{tabular}{|c|c|c|}
\hline Manner & Number of females & Percentage \\
\hline Accidental & 310 & 57.40 \\
\hline Homicidal & 37 & 6.85 \\
\hline Suicidal & 125 & 23.14 \\
\hline Natural & nil & 0.00 \\
\hline Unknown & 68 & 12.60 \\
\hline
\end{tabular}


Table 5: Show that majority of studied victims like $75.19 \%$ were from rural area, $24.81 \%$ were from urban area.

\begin{tabular}{|c|c|c|}
\hline Habitat & Number of females & Percentage \\
\hline Rural & 406 & 75.19 \\
\hline Urban & 134 & 24.81 \\
\hline
\end{tabular}

Table 6: Show that majority of the burn victims death of the studied case like $65.19 \%$ were Hindu, $15.93 \%$ were Muslims, $10 \%$ were Christians and $8.88 \%$ belongs to other religions.

\begin{tabular}{|c|c|c|}
\hline Religious & Number of females & Percentage \\
\hline Hindu & 352 & 65.19 \\
\hline Muslims & 86 & 15.93 \\
\hline Christians & 54 & 10 \\
\hline Others & 48 & 8.88 \\
\hline
\end{tabular}

\section{DISCUSSION}

During the 5 year study period from 2014 to 2018, incidence of burn were $15.55 \%, 17.78 \%, 20.74 \%, 22.23 \%, 23.70 \%$, respectively showing an increasing trend.

Females were mostly suffered burn injuries as they spend most of their time in the household activities such as cooking food, boiling water, making tea, etc. The age group having maximum number of deaths due to burn is $21-30$ years $(42.23 \%)$. This age group is the most preferred for marriage. Similar findings were shown in other studies. ${ }^{(11,12,13)}$

In this study, it was observed that $442(81.85 \%)$ cases were married and only 98 (18.15\%) were unmarried. Similar finding was also suggested in other studies. (14,15) Majority of victims were married might be because of their involvement in cooking. Dowry deaths may be another important factor. Among the manner of death, accidental $(57.40 \%)$ is more common than suicidal $(23.14 \%)$ and homicidal $(6.85 \%)$. Other studies also have similar findings. ${ }^{(16,17)}$ In present study most of the burn death belongs to rural areas (75.19\%) than urban areas $(24.81 \%)$. Another study also suggested that rural burn death predominant than urban. ${ }^{(\mathbf{1 8})}$ As we know that in rural areas as no proper equipment available for cooking and another work related to fire, so female are more susceptible for burn injuries. Many victims were related to the Hindu community (65.19\%) as compared to Muslims (15.93\%) and Christians (10\%), this findings were similar to the findings of previous studies. ${ }^{(19)}$ This may be due to the fact that in this part of the world Hinduism is the most commonly followed religion, leading to increased incidence among Hindus.

\section{CONCLUSIONS}

Married females of productive age group belonging to rural areas are worst affected in burn injuries. Regarding manner of death most of the case was accidental. Majority of the burn victim's death on the studied case was Hindu. High mortality in young married women from burns may be attributed to dowry in rural area. Awareness campaigns targeting safety precautions, opportunities for basic health education and a change in mindset of society towards females are necessary to curb this menace of burn injuries.

\section{REFERENCES}

1. Dikshit PC. Textbook of forensic medicine and toxicology. 2nd Edition. PEEPEE Publishers 2014:253-256.

2. Mohanty et al. Self inflicted Burns fatalities in Manipal. Medicine science: 2005; 45: 27 -30 .

3. Global Burden Disease Study 2013 Collaborators. Global, regional, and national incidence, prevalence, and years lived with disability for 301 acute and chronic diseases and injuries in 188 countries, 1990-2013: a systematic analysis for the Global Burden of Disease Study 2013. Lancet 2015; 386:743800.

4. GBD 2013 Mortality and Causes of Death Collaborators. Global, regional, and national age-sex specific all-cause and cause-specific mortality for 240 causes of death, 19902013: a systematic analysis for the Global Burden of Disease Study 2013.Lancet2015; 385:117-71.

5. Peck MD. Epidemiology of burns throughout the world. Part I: Distribution and risk factors. Burns 2011; 37:1087-100.

6. Sanghavi P, Bhalla K, Das V. Fire-related deaths in India in 2001: a retrospective analysis of data. Lancet 2009; 373:1282-8.

7. Ganesamoni S, Kate V, Sadasivan J. Epidemiology of burn patients in atertiary care centre in South India. Burns 2010; 36:422-9.

8. Van Rijn JL Olga, Bouter LM, Meertens RM. The aetiology of burns in developed 
countries: review of the literature. Burns. 1989; 15(4):217-21.

9. Tomar J, Mishra PK, Sane MR,et.al. Epidemiology and Outcome of Burn Injuries, Prospective study. Indian Journal of Forensic Medicine and Community Medicine, 2019; 04(1):59-63.

10. Mangal HM, Pathak A, Rathod JS. The Fire is "A Scourge\&Blessing to the Mankind" JIAFM, 2007, 29(4) 75-77.

11. Harish D, Kaur C, Singh A,et.al. A Comprehensive Analysis of Deaths due to Burns in a Tertiary Care Centre. J Punjab Acad Forensic Med Toxicol, 2013, 13(2) 68-73.

12. Prasad CS, Shubendu K, Gawasker SP,SK Nawal. Profile of Burn Injuries among Autopsies Conducted in Department of FMT, RIMS, Ranchi: IOSRJDMS, 2017; Vol.16, no.08:53-57.

13. Memchoubi, H. Nabachandra. A Study of Burn Deaths in Imphal. J IAFM, 2007, 29(4) 131-134.

14. Gaffar UB, Husain M, Rizvi SJ. Thermal Burn: An Epidemiological Prospective Study. J Indian Acad Forensic Med, 2008, 30(1).
15. Mangal HM, Pathak A, Rathod JS. The Fire is Both "A Blessing \& Scourge to the Mankind" JIAFM, 2007, 29(4) 75-77.

16. Ahmed I, Farooq U, Afzal W, Salman Medico legal aspect of burn victims: A ten years study. Pak J Med Sci 2009; 25(5); pp: 797-800.

17. Dr. Kulshrestha P.K, Dr. Sharma R.K., Dr.Dogra DasTirath; the Study of Demographical and Sociological Variables of Unnatural Deaths among Women in South Delhi within Seven Years of Marriage.; Journal of Punjab Academy of Forensic Medicine

18. Dr. N. P. Zanjad, Dr. H. V. Godbole. Study of Fatal Burn Cases in Medico- Legal Autopsies JIAFM, 200729 (3); ISSN: 09710973.

19. Singh P. Incidence of Post Burn Septicaemia in tertiary care hospital, JIAFM. 2011; 33(4): 317-320.

How to cite this article: Ranjan K, Singh RR, Das RR et.al. Thermal burn deaths: a retrospective study on female victims in Bihar. International Journal of Research and Review. 2021; 8(2): 13-16. 